\title{
STUDY OF MODE - I FRACTURE PARAMETERS IN HIGH PERFORMANCE CONCRETE
}

\author{
Y.Murali Krishna $M^{1}$, Ch.N.Satish Kumar ${ }^{2}$ \\ ${ }^{1}$ Assistant professor, Department of Civil Engineering, Bapatla Engineering College, Bapatla-522101, India \\ ${ }^{2}$ Professor, Department of Civil Engineering, Bapatla Engineering College, Bapatla-522101, India
}

\begin{abstract}
In this paper an experimental investigation was carried out to study the fracture behavior of plane high performance concrete beams subjected to three point bending. In this investigation to study the effect of stress intensity factor and Fracture energy of concrete beams of various sizes with constant notch depth ratios at center. It was found that the stress intensity factor and fracture energy increases with the increasing of beam sizes and decreasing the failure stresses with increasing the beam sizes.
\end{abstract}

Keywords: Stress intensity factor, Fracture energy

\section{INTRODUCTION}

Concrete is often considered a heterogeneous material in engineering design and construction, yet is in reality a composite consisting of mortar matrix and aggregate inclusion phases. Upon closer inspection, voids are apparent, as the cement paste is actually a mixture of different types of crystalline structures at various degrees of hydration with trapped and entrained air voids. Most researchers simplify concrete as a two-phase composite consisting of mortar and aggregate; to complete the model, defects known as 'microcracks' are introduced in the system. The failure process is initiated when minute bond cracks format mortar-aggregate interfaces, while small cracks may also occur in the mortar and aggregate phases separately. Fracture of these microcracks gives concrete the semblance of ductility; it is the brittle propagation of many microcracks that form a semi-ductile propagation of a microcrack and ultimately lead to material failure. In fracture mechanics terminology there are three different cracking modes defined: (i) mode I- opening mode, (ii) mode II - shearing mode and (iii) mode III- tearing mode. At the macro scale level they describe three independent kinematic movements of the upper and lower crack surface with respect to each other and are sufficient to define all possible modes of crack propagation in an elastic material. Of course, at the micro scale the stress distribution is much more complex and at such a level modes of fracture have no sense. As far as concrete is concerned, mode I is a relatively clear type of crack propagation. On the contrary, mode II and III are complex failure modes, which can hardly be realized in an experiment. In these modes the stress normal to the crack surface need to be approximately zero and only in-plane shear stress should exist. Even when these conditions can be realized, due to the complexity of the concrete structure, over a concrete crack surface a combination of different stresses exist (shear, tension, compression and bending). Although the resulting stress may be in-plane stress (shear), complex stress-strain conditions on a crack surface make the identification of mode II and III fracture parameters extremely difficult.
Moreover, the question arises whether in a sense of linear elastic fracture mechanics these two failure modes even exist. The similar complex combination of stresses exists for mode I fracture type as well, however, the stress and strain perpendicular to the crack surface dominate at this fracture type. large number of experimental results of crack initiation and propagation in mixed mode on notched beams are based on the Iosipescu geometry (Iosipescu, 1967; Arrea and Ingraffea, 1982; Bažant and Pfeiffer, 1986; Biolzi, 1990; Bocca et al., 1991; Schlangen, 1993a, b; Swartz and Taha, 1990) and the results developed in the RILEM 89-FMT Committee (Ballatore et al., 1990; Bocca et al., 1990), among others. Other sets of experimental results are based on the three point bend of notched beams with eccentric notch: (Guo et al., 1994a,b; Jenq and Shah, 1988; Swartz et al. 1988a), among others. Moreover, there are experimental results developed on notched cylinders (Barr et al., 1989) and double notched prismatic specimens (Bažant and Pfeiffer, 1986; Schlangen, 1993a; Barr and Deradj, 1990; Davies, 1989). The advance has been important, but some aspects need to be studied in depth $[1,2]$.

In the present paper, our main attention is to study the influence of notch of high performance concrete beams of various sizes and e with constant notch depth ratio with constant mix proportions on mode-I stress intensity factor, fracture energy and failure stresses.

\section{EXPERIMENTAL PROGRAM}

The experimental program was designed to study the stress intensity factor and fracture energy of plain-high performance concrete beams of size $75 \mathrm{~mm} \times 75 \mathrm{~mm} \times$ $350 \mathrm{~mm}$ (Span is $300 \mathrm{~mm}$ ), $75 \mathrm{~mm} \times 150 \mathrm{~mm} \times 650 \mathrm{~mm}$ (Span is $600 \mathrm{~mm}$ ) and $75 \mathrm{~mm} \times 300 \mathrm{~mm} \times 1250 \mathrm{~mm}$ (Span is $1200 \mathrm{~mm}$ ) with constant notch at center of the beam under a three point bending test i.e., with a central point load. The influence of notch of specimens on stress intensity and fracture energy was studied on beams of varying size effects with constant mix proportion (M30). 
This experimental program consists of three series of beams for high performance of constant proportion given in table 1 , namely small, medium, and large and having equal notch depth ratio (0.15). Fig shows the schematic arrangement of the beam specimen subjected to three point bending.

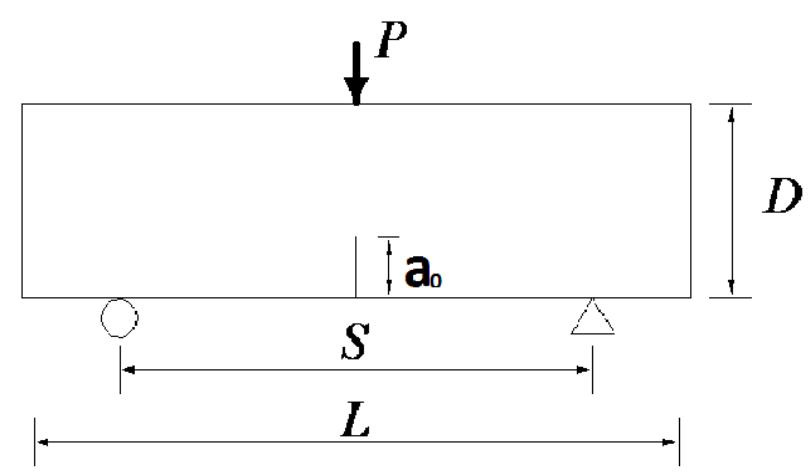

\section{MATERIAL DETAILS:}

Ordinary Portland cement (OPC) of 53 grade conforming to IS 8112:1989 with specific gravity of 3.15 was used in Concrete mix [6]. Fine aggregate conforming to Zone II of IS 383:1970 was used[7].Crushed coarse aggregate passing through $20 \mathrm{~mm}$ sieve and retained on $10 \mathrm{~mm}$ sieve $(100 \%)$ with specific gravity 2.7 was used. Robo Sand or crusher dust obtained from local granite crushers was used in concrete and also GGBS is used in concrete.

The details of mix proportions are listed in Table.

\begin{tabular}{|l|l|l|l|l|l|l|l|l|l|}
\hline $\begin{array}{l}\text { Grade of } \\
\text { concrete }\end{array}$ & Specimen & $\begin{array}{l}\text { Aggregate } \\
\text { Size } \\
(\mathrm{mm})\end{array}$ & $\begin{array}{l}\text { Length,L, } \\
(\mathrm{mm})\end{array}$ & $\begin{array}{l}\text { width,b, } \\
(\mathrm{mm})\end{array}$ & $\begin{array}{l}\text { Depth,d, } \\
(\mathrm{mm})\end{array}$ & $\begin{array}{l}\text { Span,S, } \\
(\mathrm{mm})\end{array}$ & $\begin{array}{l}\text { Notch } \\
\text { Depth } \\
(\mathrm{a} 0)\end{array}$ & a0/d & S/d \\
\hline \multirow{3}{*}{ M30 } & Small & 20 & 350 & 75 & 75 & 300 & 11.25 & 0.15 & 4 \\
\cline { 2 - 10 } & Medium & 20 & 650 & 75 & 150 & 600 & 22.5 & 0.15 & 4 \\
\cline { 2 - 10 } & Large & 20 & 1250 & 75 & 300 & 1200 & 45 & 0.15 & 4 \\
\hline
\end{tabular}

\section{CASTING}

Cubes of $150 \mathrm{~mm}$ size were used to determine the compressive strength of concrete. Cylinders with $150 \mathrm{~mm}$ diameter and $300 \mathrm{~mm}$ length were used to determine the splitting tensile strength of concrete. Specially made wooden specimens are used for casting prisms. The moulds were tightly fitted and all the joints were sealed by plaster of Paris in order to prevent leakage of cement slurry through the joints. The inner side of the moulds was thoroughly oiled before going for concreting. The mix proportions were put in miller and thoroughly mixed.

The prepared concrete was placed in the moulds and is compacted using needle\& plate vibrators. The same process is adopted for all specimens. After specimens were compacted the top surface is leveled with a trowel. The specimens were removed from the moulds after 24 hours of casting, the specimens were placed in water for curing. All the specimens were water cured for 28 days. After removing the specimens from the curing tank they are allowed to dry for some period. They were cleaned with cotton waste to remove the dust particles. All the specimens were white washed with white cement. For notch, beams were cut with a marble cutter in to the hardened concrete. In this experimental investigation a total of eighteen concrete beams were casted.

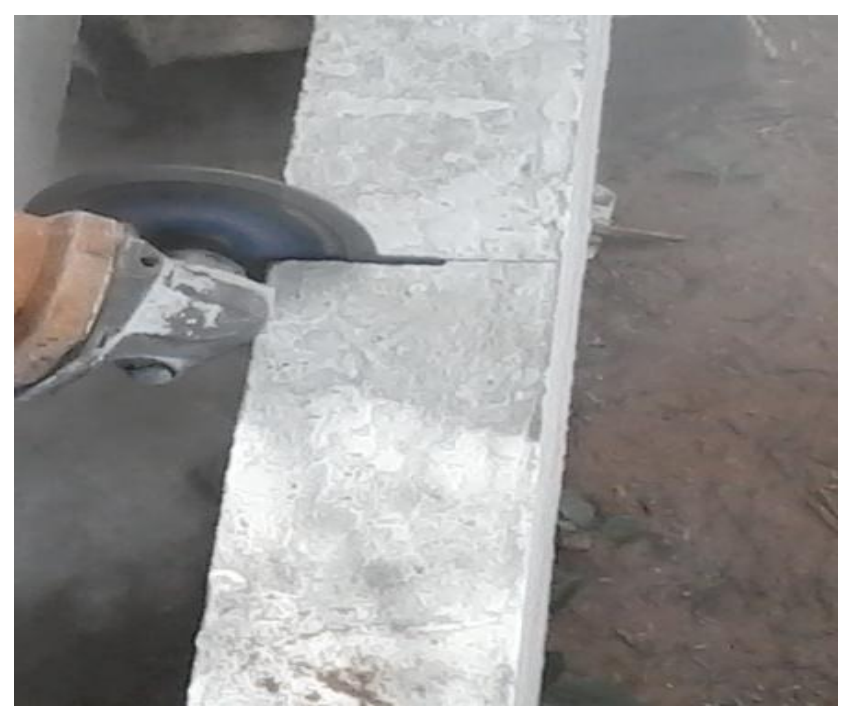

Cutting beam with marble cutter

\section{TEST SETUP AND TESTING PROCEDURE:}

All the beam specimens were tested on the loading frame testing Machine of 100 tons capacity under displacement rate control and cubes and cylinders on UTM. The beam specimen was kept at the center of testing machine. Beam specimens were put on roller supports exactly under the centre of the load point. For finding the compressive strength of the cube, split tensile strength of the cylinder and the modulus of rupture of the prism specimens were tested on the UTM. The specimen was placed in the machine in such manner that the load was applied on the axis of the specimen was carefully aligned at the center of the loading 
frame .The load was applied without shock and increased continuously at a constant rate until the resistance of the specimen to the increasing load breaks down and no greater can be sustained. The maximum load applied on the specimen was recorded.
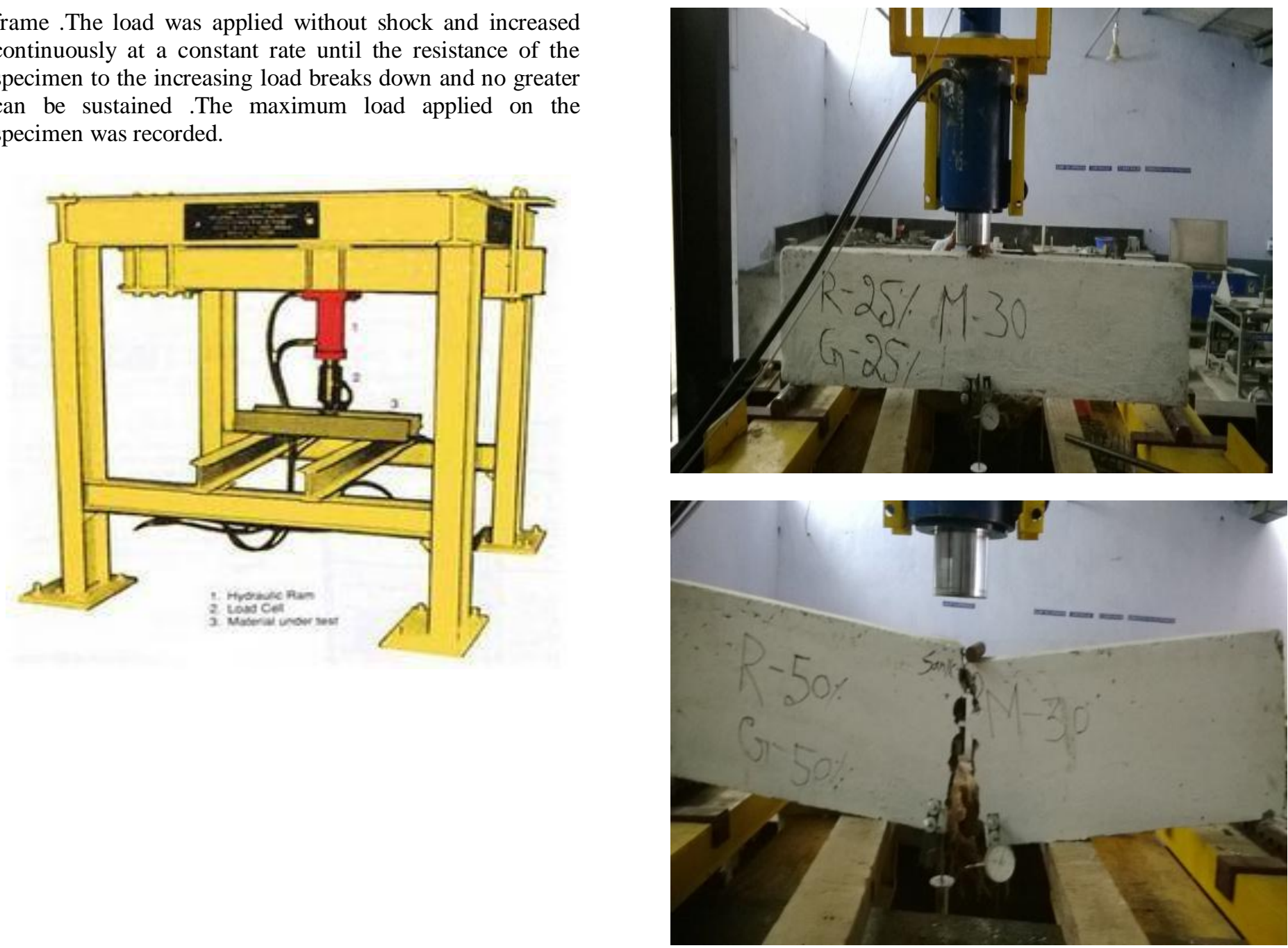

\section{Quantities of Materials}

\begin{tabular}{|l|l|l|l|l|l|l|l|l|l|}
\hline $\begin{array}{l}\text { Grade of } \\
\text { concrete }\end{array}$ & $\begin{array}{l}\text { Size of } \\
\text { aggregate }\end{array}$ & $\%$ of mix & $\begin{array}{l}\text { Mix } \\
\text { proportion }\end{array}$ & Cement & $\begin{array}{l}\text { Fine } \\
\text { aggregate }\end{array}$ & $\begin{array}{l}\text { Coarse } \\
\text { aggregate }\end{array}$ & water & GGBS & $\begin{array}{l}\text { ROBO } \\
\text { SAND }\end{array}$ \\
\hline M30 & $20 \mathrm{~mm}$ & R25\%-25\% & $1: 1.26: 3.12$ & 312.375 & 394.275 & 1300.3 & 0.46 & 104.125 & 131.425 \\
\hline M30 & $20 \mathrm{~mm}$ & R30\%-50\% & $1: 1.26: 3.12$ & 208.25 & 367.99 & 1300.3 & 0.46 & 208.25 & 157.71 \\
\hline M30 & $20 \mathrm{~mm}$ & R50\%-50\% & $1: 1.26: 3.12$ & 208.25 & 262.85 & 1300.3 & 0.46 & 208.25 & 262.85 \\
\hline M30 & $20 \mathrm{~mm}$ & R0\%-G 0\% & $1: 1.26: 3.12$ & 416.5 & 525.7 & 1300.3 & 0.46 & 0 & 0 \\
\hline
\end{tabular}

\section{Mechanical Properties of Concrete}

Table 2: Mechanical properties of concrete

\begin{tabular}{|l|l|l|l|l|}
\hline Grade of concrete & \% of prapotion & mix proportion & fck (N/mm2) & ft (N/mm2) \\
\hline M30 & R-25\%G25\% & $1: 1.26: 3.12$ & 40.12 & 3.6 \\
\hline M30 & R-30\%G-50\% & $1: 1.26: 3.12$ & 48.89 & 3.8 \\
\hline M30 & R-50\%G-50\% & $1: 1.26: 3.12$ & 46.79 & 4.1 \\
\hline M30 & R-0\%G-0\% & $1: 1.26: 3.12$ & 37.1 & 3.2 \\
\hline
\end{tabular}

\section{RESULTS AND DISCUSSIONS:}

Based on the tests on Concrete beams it can be observed that, in the case of centrally notched plain and high performance concrete beams, the first crack appeared at notch tip. The deflections were measured only up to the ultimate load and failed suddenly in to two pieces. 
Table 5.1: Failure loads, Nominal stresses, Stress Intensity Factors

\begin{tabular}{|c|c|c|c|c|c|}
\hline \multirow[t]{2}{*}{$\%$ mix } & \multirow{2}{*}{$\begin{array}{l}\text { Concrete } \\
\text { grades }\end{array}$} & \multirow{2}{*}{ Specimen } & $\mathbf{p}_{\max }$ & $\square_{\square}$ & $\mathbf{K}_{\mathbf{I}}$ \\
\hline & & & $\mathrm{KN}$ & $\left(\mathrm{N} / \mathrm{mm}^{2}\right)$ & $\left(\mathrm{N} / \mathrm{mm}^{2}\right) \sqrt{\mathrm{mm}}$ \\
\hline \multirow{3}{*}{$\mathrm{R} 25 \% \mathrm{G} 25 \%$} & \multirow{3}{*}{ M 30} & Small & 5.02 & 5.35 & 31.78 \\
\hline & & Medium & 9.08 & 4.84 & 40.21 \\
\hline & & Large & 15.33 & 4.09 & 47.99 \\
\hline \multirow{3}{*}{ R30\%G50\% } & \multirow{3}{*}{ M 30} & Small & 6.02 & 6.42 & 38.11 \\
\hline & & Medium & 11.08 & 5.91 & 49.06 \\
\hline & & Large & 18.33 & 4.89 & 57.38 \\
\hline \multirow{3}{*}{ R50\%G50\% } & \multirow{3}{*}{ M 30} & Small & 7.02 & 7.49 & 44.44 \\
\hline & & Medium & 13.08 & 6.98 & 57.91 \\
\hline & & Large & 22.3 & 5.95 & 69.89 \\
\hline \multirow{3}{*}{ R0\% G0\% } & \multirow[t]{3}{*}{ M30 } & Small & 4.02 & 4.29 & 25.45 \\
\hline & & Medium & 7.08 & 3.78 & 31.65 \\
\hline & & Large & 12.33 & 3.29 & 38.60 \\
\hline
\end{tabular}

Fracture Energy, Brittleness number, Cohesive Fracture Zone length

\begin{tabular}{|l|l|l|l|}
\hline \multirow{2}{*}{ Specimen } & $\mathbf{G}_{f}$ & & $\mathbf{C}_{f}$ \\
\cline { 2 - 2 } Small & $\mathrm{j} / \mathrm{m}^{2}$ & 0.30 & $\mathrm{~mm}$ \\
\hline Medium & 136.31 & 0.60 & 28.36 \\
\hline Large & 136.31 & 1.21 & 28.36 \\
\hline Small & 165.10 & 0.33 & 28.36 \\
\hline Medium & 165.10 & 0.67 & 25.48 \\
\hline Large & 165.10 & 1.35 & 25.48 \\
\hline Small & 327.44 & 0.21 & 25.48 \\
\hline Medium & 327.44 & 0.43 & 39.25 \\
\hline Large & 327.44 & 0.87 & 39.25 \\
\hline Small & 96.00 & 0.27 & 39.25 \\
\hline Medium & 96.00 & 0.54 & 31.57 \\
\hline Large & 96.00 & 1.09 & 31.57 \\
\hline
\end{tabular}




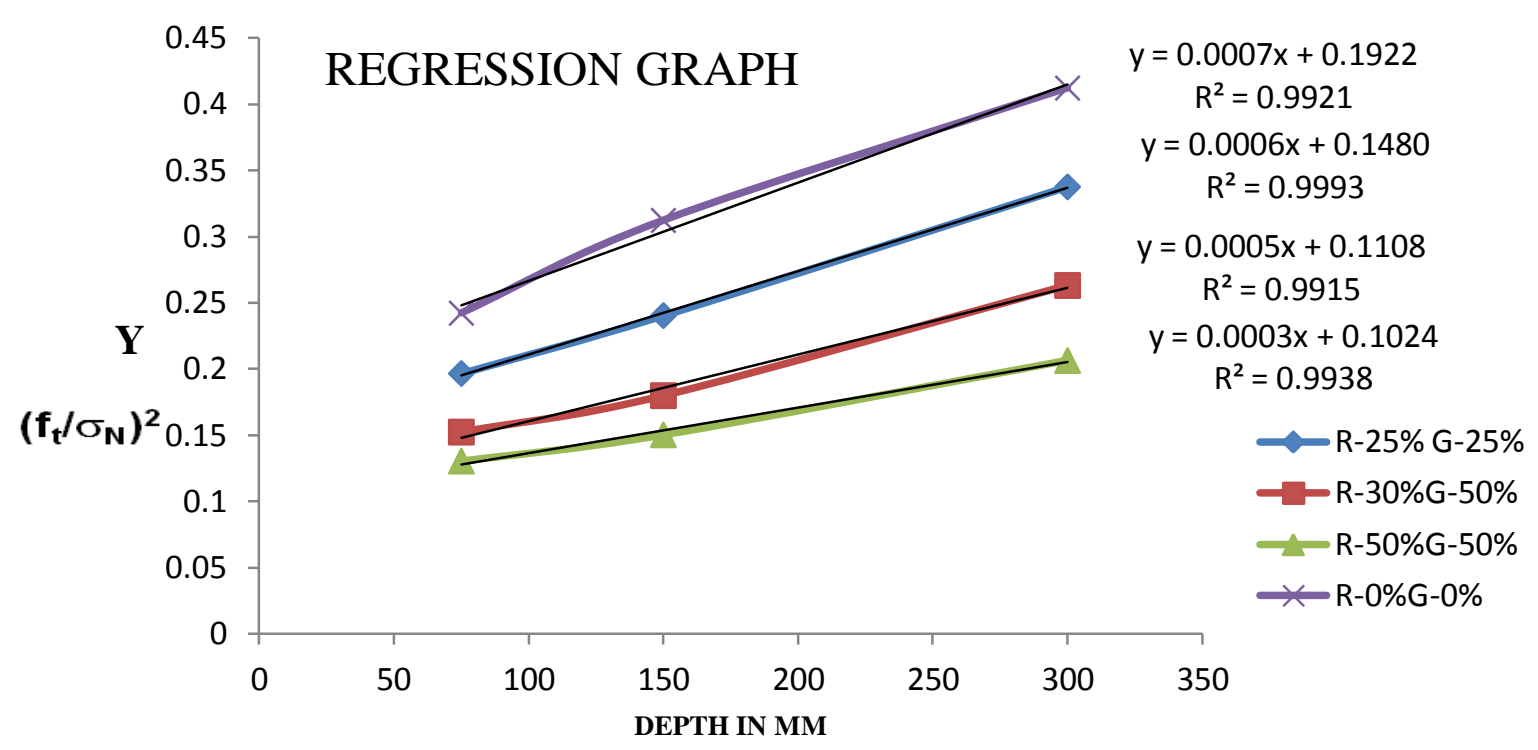

Regression graphs

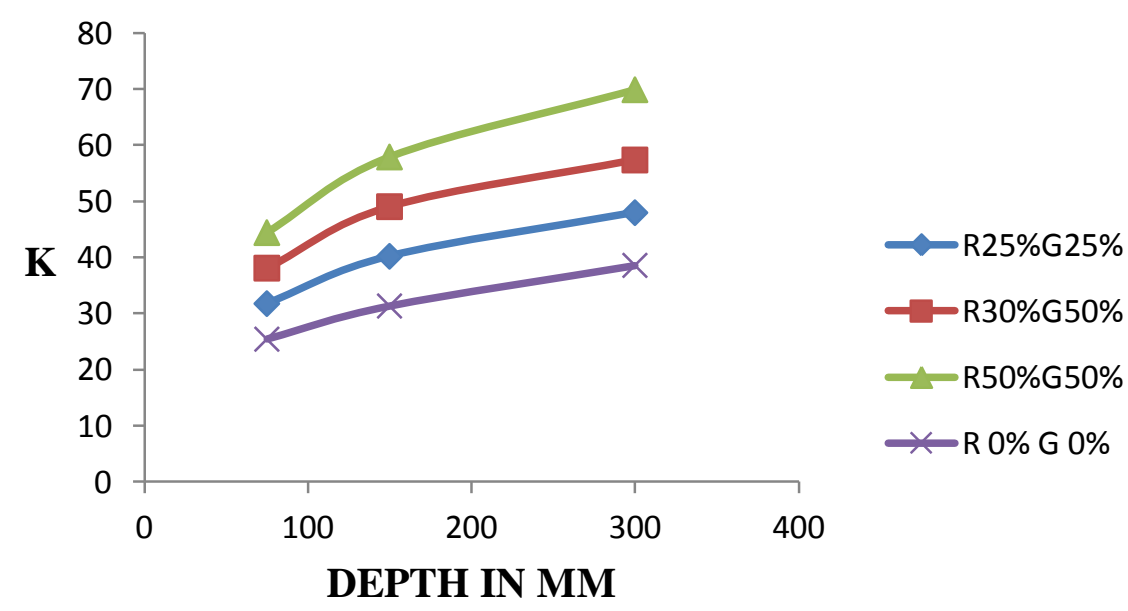

Stress Intensity Factor curves for Depth of beams

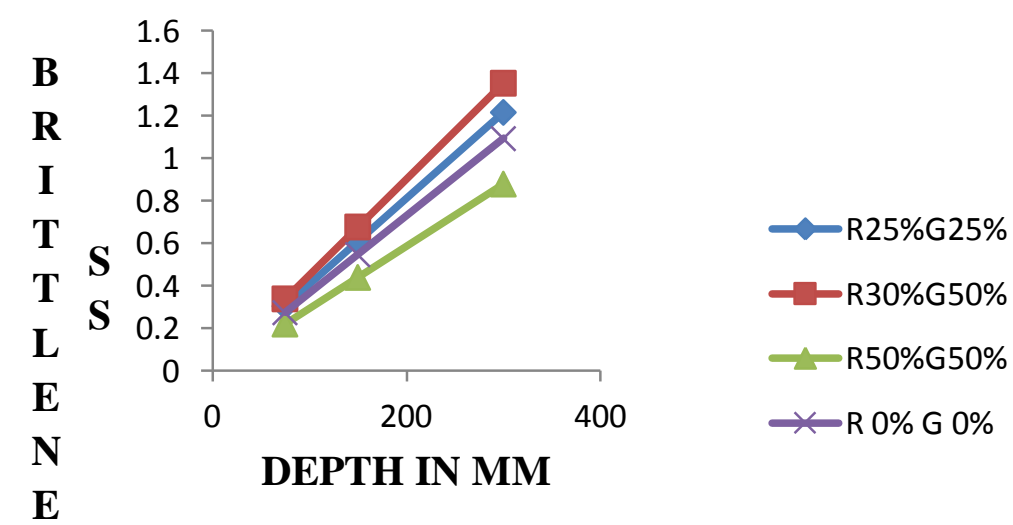

Brittleness number curves for Depth of beams 


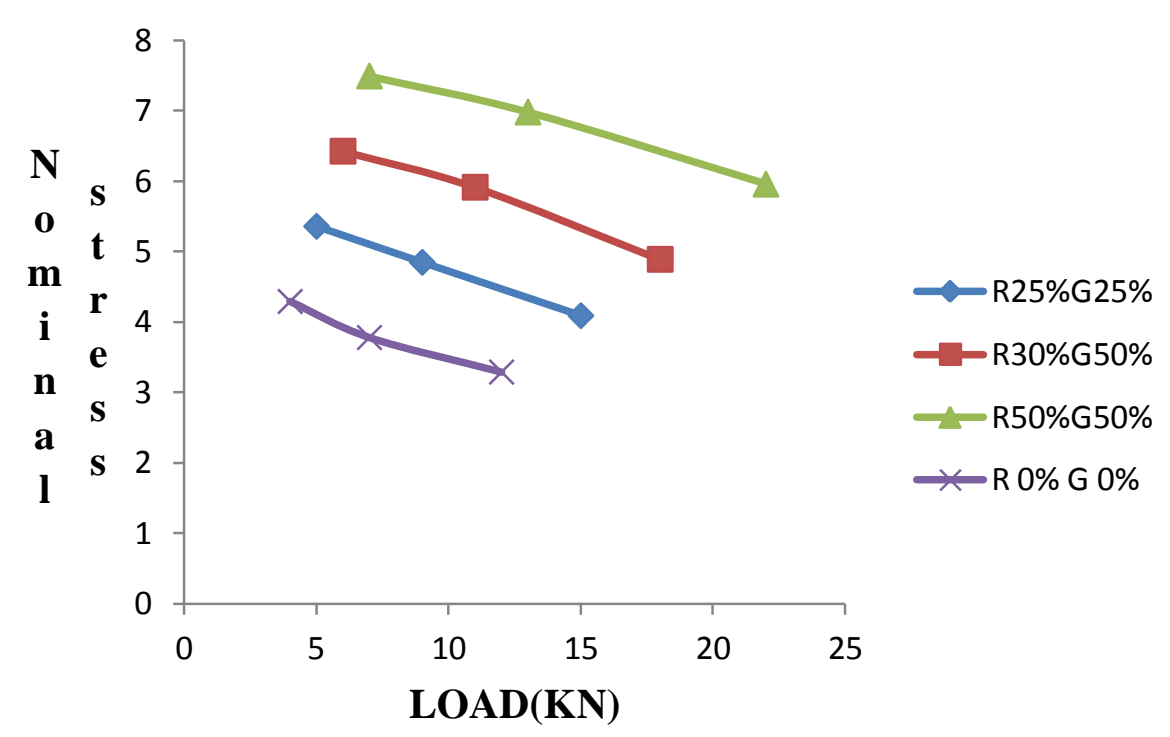

Nominal Stresses Vs Load graph
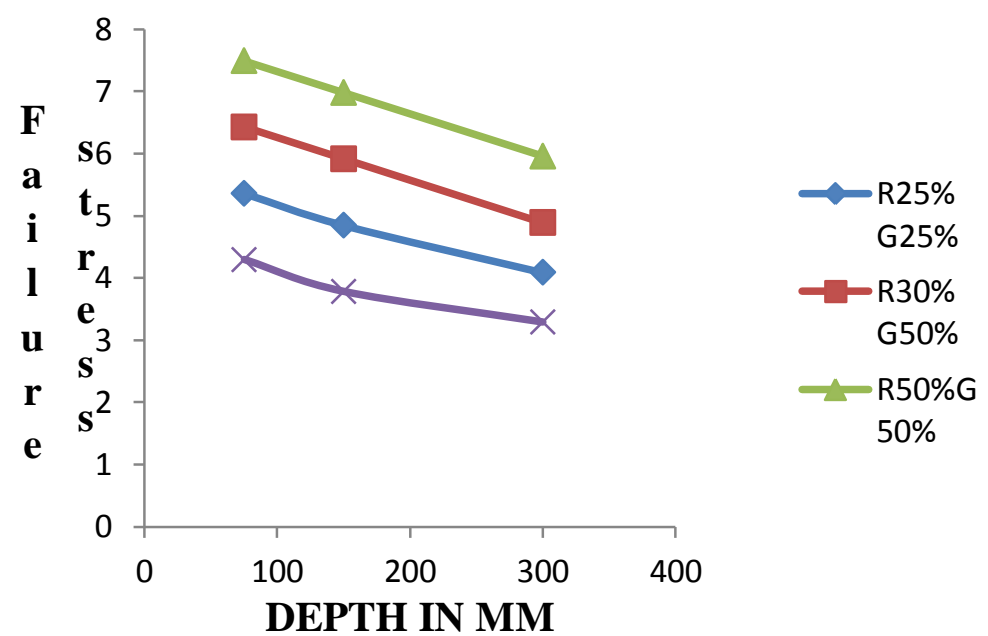

Failure stress Vs Depth

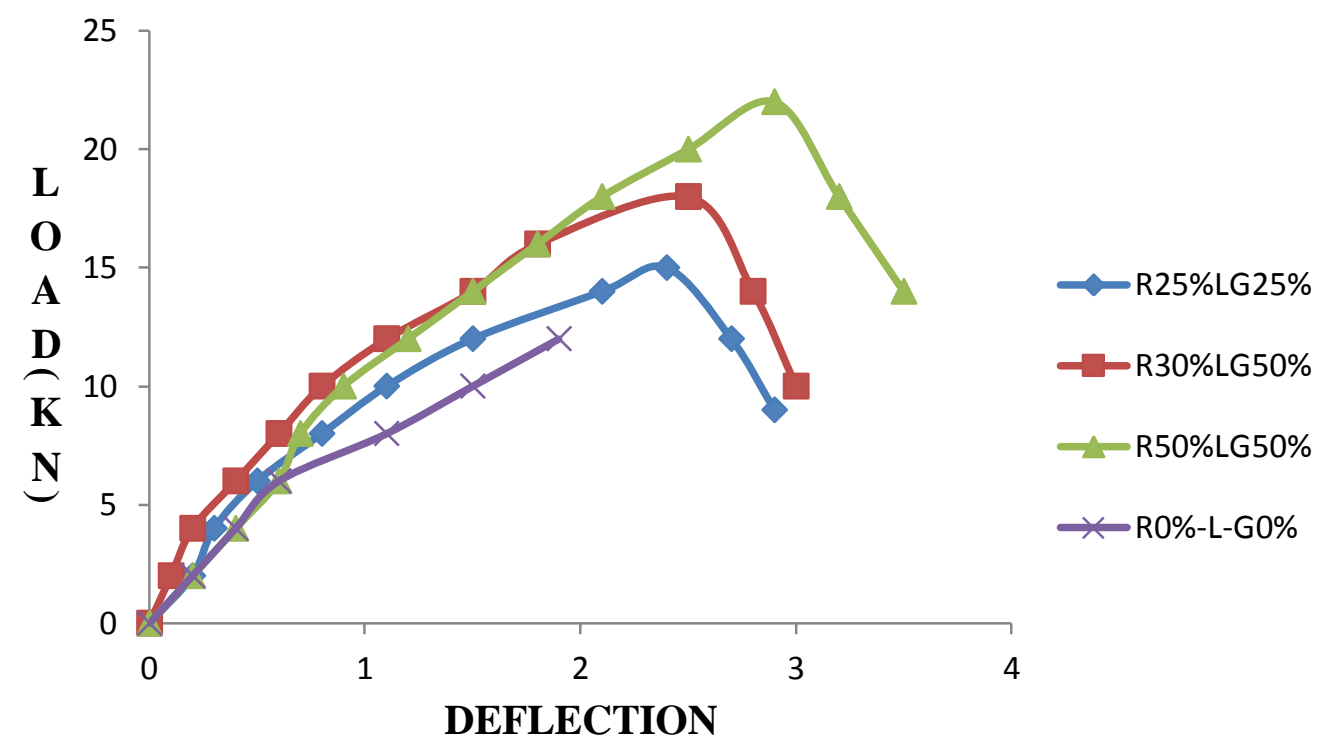

Load Vs Displacement graph for M 30 grade large beams 


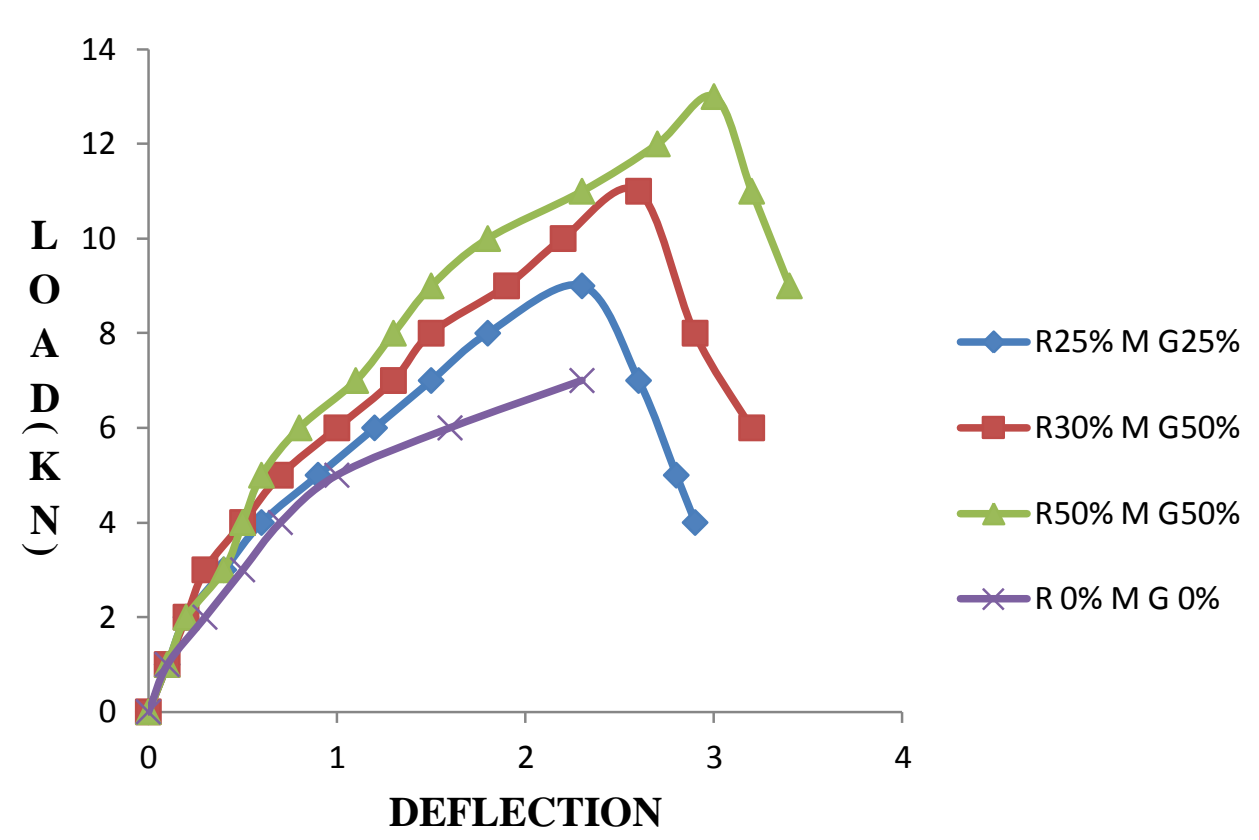

Load Vs Displacement graph for M30 grade Medium beams

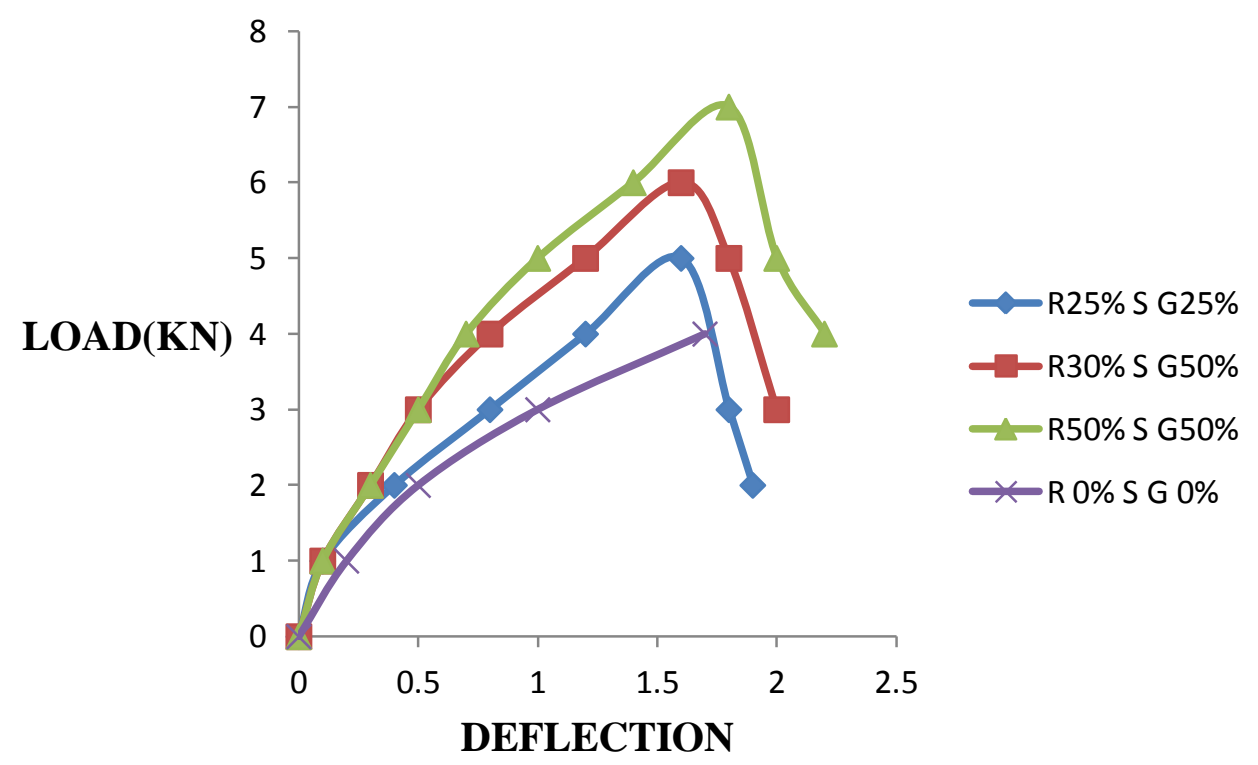

Load Vs Displacement graph for M 30 grade Small beams

\section{CONCLUSION}

Based on the tests on eighteen notched concrete beam specimens, the following conclusions have been drawn:

1. It is observed that, failure stresses (nominal stresses) decreases with increasing of beam sizes.

2. It is also observed that, stress intensity factor increases with increase in beam sizes for all persentage of mix praporations of concrete.

3. It is also observed that, stress intensity factor increases with increase in compressive strength of beams.

4. It is also observed that, Fracture energy decreases with increase in compressive strength of concrete.
5. It is also observed that, Brittleness number increases with increase in size of the specimen.

6. It is also observed that, Brittleness number increases with increase in compressive strength of the specimen

7. It is also observed that, fracture parameters are higher in highperformence concrete when compare to ordinary concrete 

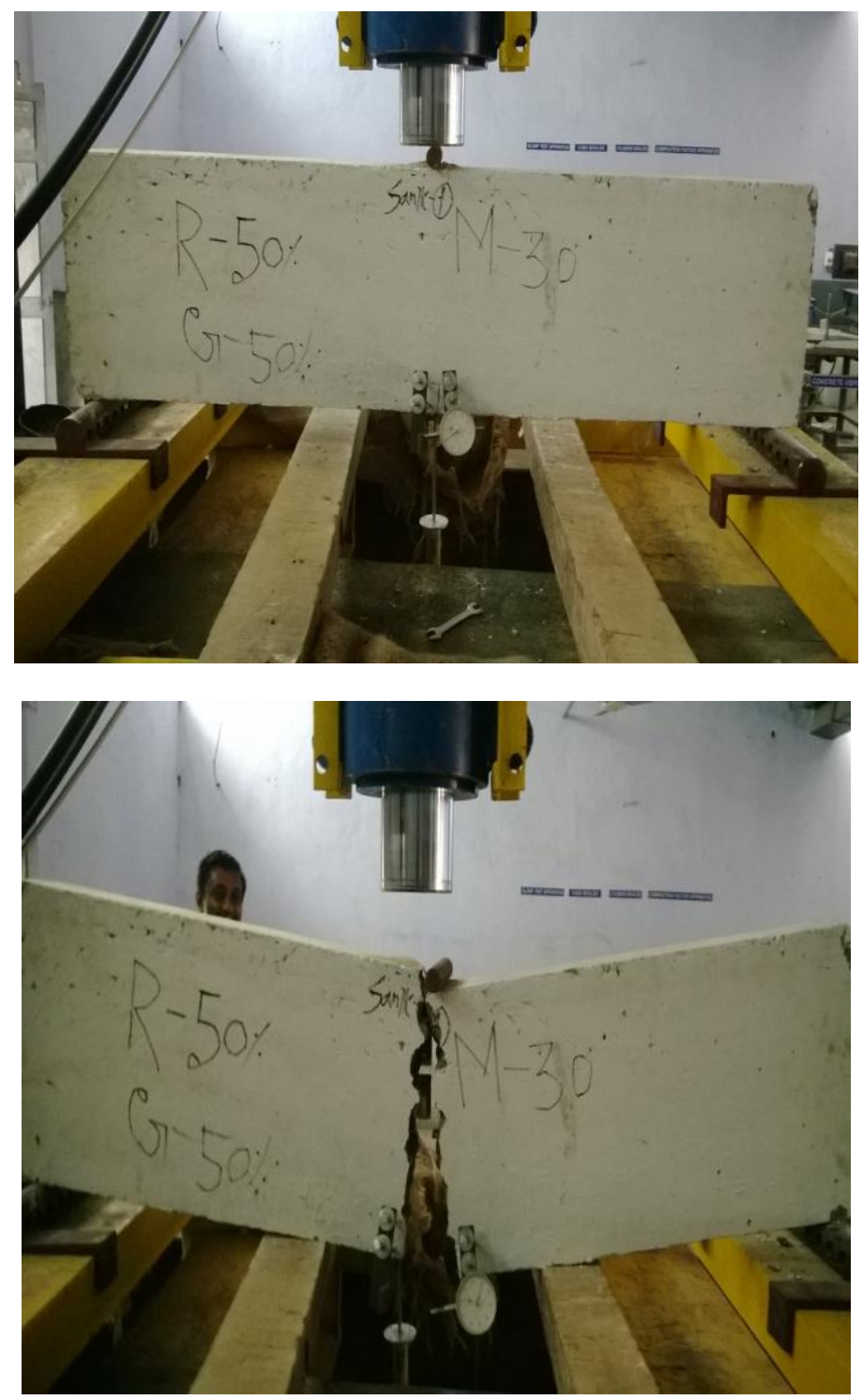

large beams before and after loading

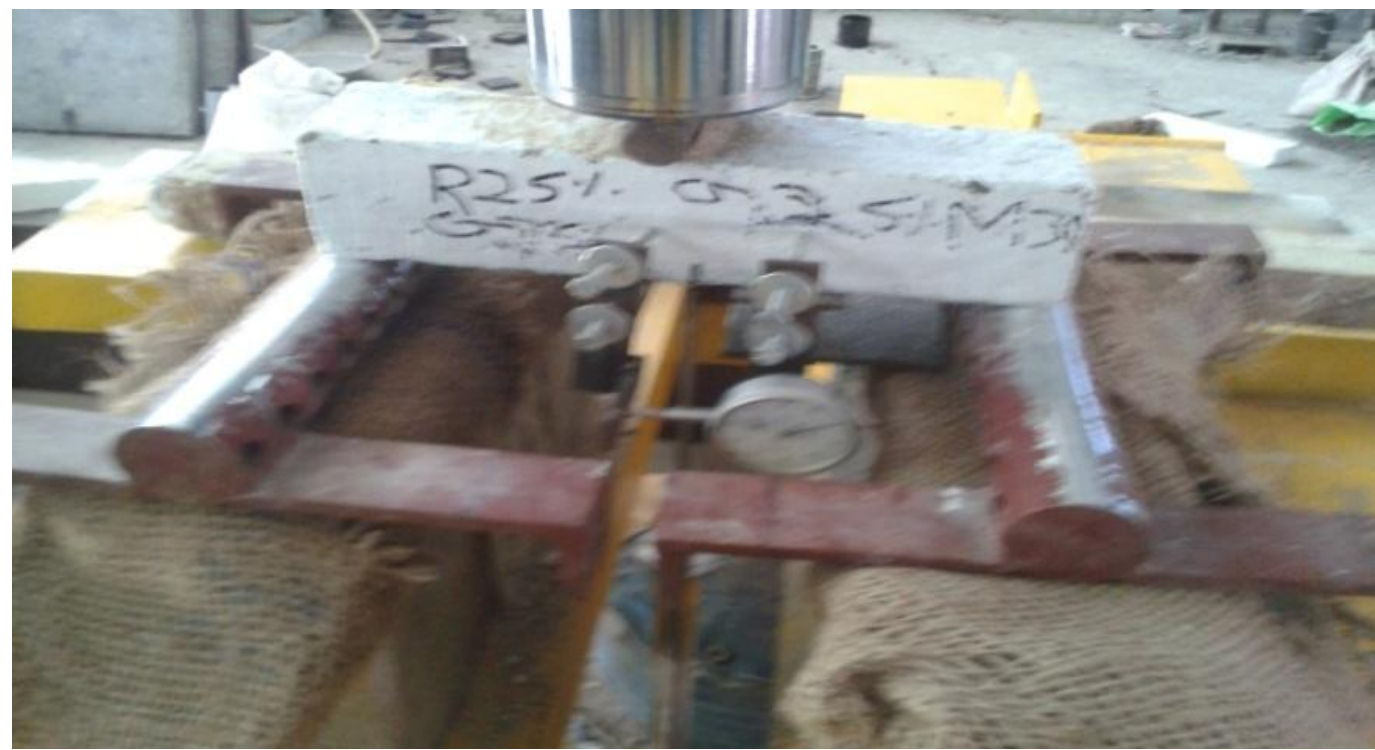




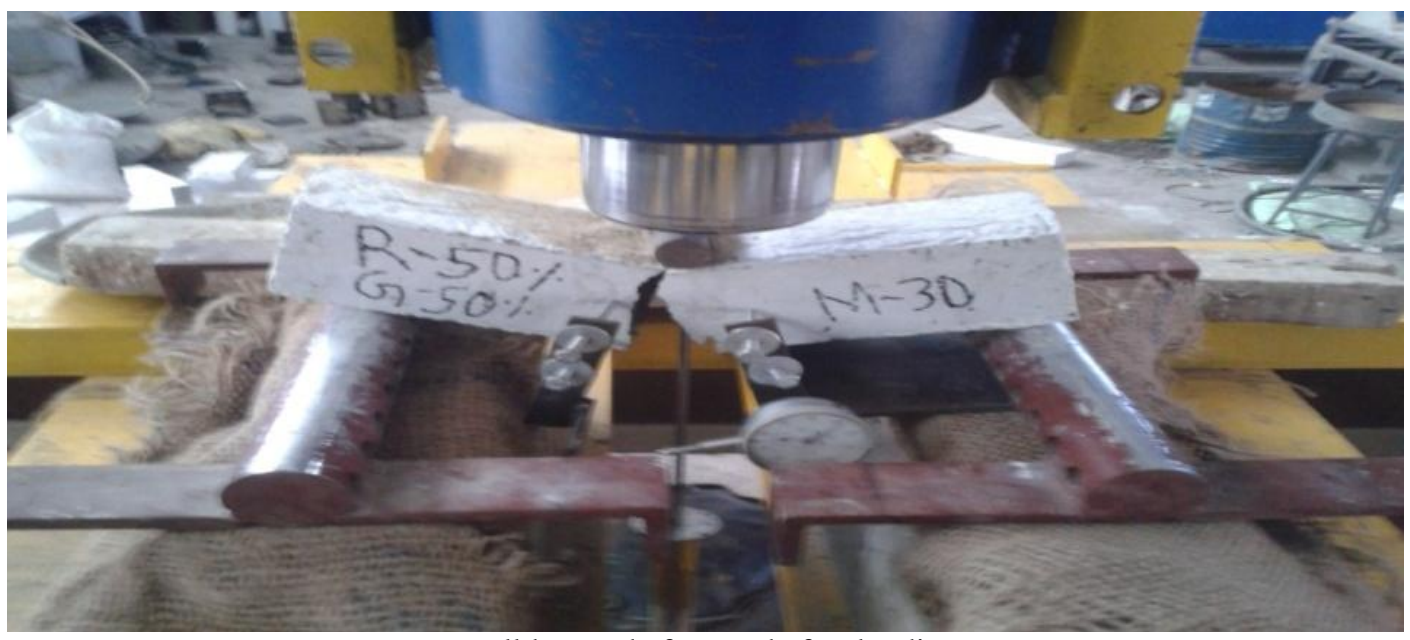

small beams before and after loading
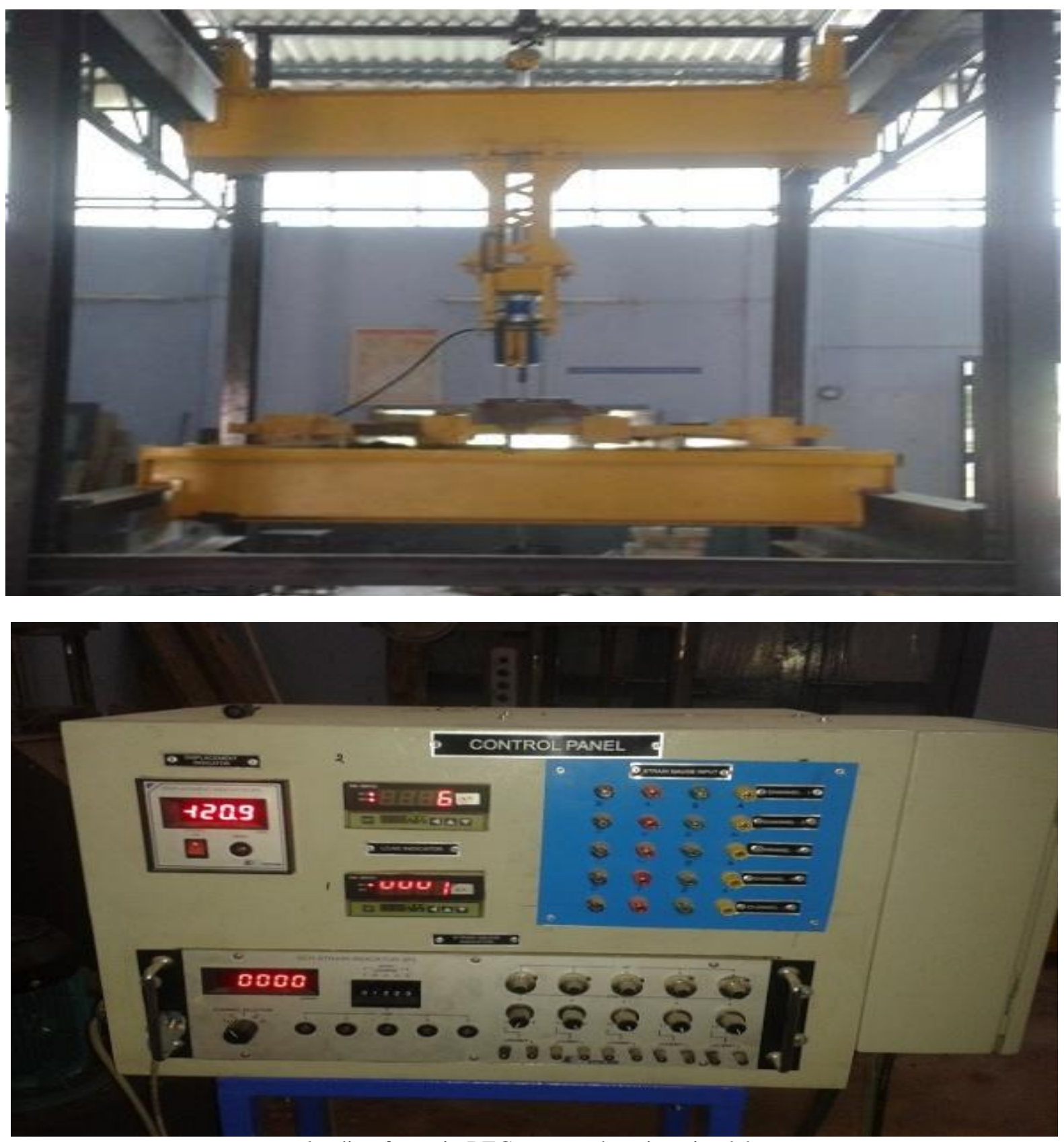

loading frame in BEC structural engineering lab 


\section{ACKNOWLEDGEMENTS}

The authors are highly thankful to the authorities of bapatla engineering college, bapatla, for providing facilities for carrying out this work.

\section{REFERENCES}

[1] R. Vidya Sagar, S.V. Dinesh and A.C. Santosh 2005 has done an experimental investigation on fracture energy of normal and high strength concrete (HSC) beams.

[2] P. N. RAO in 2010 has done his investigation on High Performance Concrete.

[3] Bhushan, L Karihaloo 1995 has done Fracture mechanics and structural concrete,

[4] BazÏant, Z.P., 1984. Size effect in blunt fracture: Concrete, rock, metal. J. of Engng.

[5] Mechanics, ASCE 110, 518 \pm 535 .

[6] Bazant, Z. P. (1983a) 'Size effect in brittle failure of concrete structures', Report No83-

[7] 2/? 65 , Center for Concrete and Geomaterials, Northwestern University, Evanston,

[8] Illinois; also Jour. of Engng. Mech. ASCE, 110 (1984),518-535.

[9] Bazant ,Z P and kazemi,M.T .Determination of fracture energy,process zone,length and brittleness number from size effect with application to rock and concrete,IJF,1990 Vol,pp.121-138.

[10] .Bazant, Z.P., 1998. Size effect in tensile and compression fracture of concrete structures: computational modeling and design. In:

[11] Bazant, Z. P. (1983a) 'Size effect in brittle failure of concrete structures', Report No. 83- 2/?65 , Center for Concrete and Geomaterials, Northwestern University, Evanston, I.llInOls; also Jour. of Engng. Mech. ASCE, 110 (1984),518-535.

[12] Z.P. Bazant and M.T. Kazemi, "Brittleness and size effect in concrete structures", Engineering Foundation Conference on "Advances in Cement Manufacture and Use", Potosi, Missouri (Aug. 1988).

[13] Z.P. Bazant, S. Lee and P.A. Pfeiffer, Engineering Fracture Mechanics 26, No. I (1987) 45-57

[14] Misra. V. N., 1984, Indian Concrete Journal, August, vol. 58(8), pp 219-223.

[15] Ahmed E. Ahmed and Ahmed A. EI. Kourd, 1989, American Concrete Institute Materials Journal, JulAug, pp. 417 - 424.

[16] Indian Standards 8112 - 1989: 43 Grade Ordinary Portland cement Specification.

[17] Indian Standards 456 - 2000: Plain and Reinforced Concrete Code of Practice. 